\title{
Controlled delivery of BID protein fused with TAT peptide sensitizes cancer cells to apoptosis
}

\author{
Emilia Joanna Orzechowska', Ewa Kozlowska ${ }^{1}$, Alicja Czubaty ${ }^{1}$, Piotr Kozlowski ${ }^{1}$, Krzysztof Staron ${ }^{1}$ \\ and Joanna Trzcinska-Danielewicz ${ }^{1 *}$
}

\begin{abstract}
Background: Low cellular level of BID is critical for viability of numerous cancer cells. Sensitization of cells to anticancer agents by BID overexpression from adenovirus or pcDNA vectors is a proposed strategy for cancer therapy; however it does not provide any stringent control of cellular level of BID. The aim of this work was to examine whether a fusion of BID with TAT cell penetrating peptide (TAT-BID) may be used for controlled sensitization of cancer cells to anticancer agents acting through death receptors (TRAIL) or DNA damage (camptothecin). Prostate cancer PC3 and LNCaP, non-small human lung cancer A549, and cervix carcinoma HeLa cells were used in the study.

Methods: Uptake of TAT-BID protein by cells was studied by quantitative Western blot analysis of cells extracts. Cells viability was monitored by MTT test. Apoptosis was detected by flow cytometry and cytochrome c release assay.

Results: TAT-BID was delivered to all cancer cells in amounts depending on time, dose and the cell line. Recombinant BID sensitized PC3 cells to TRAIL or, to lesser extent, to camptothecin. Out of remaining cells, TAT-BID sensitized A549, and only slightly HeLa cells to TRAIL. None of the latter cell lines were sensitized to camptothecin. In all cases the mutant not phosphorylable by CK2 (TAT-BID ${ }^{\text {T59AS76A }}$ ) was similarly efficient in sensitization as the wild type TAT-BID.

Conclusions: TAT-BID may be delivered to cancer cells in controlled manner and efficiently sensitizes PC3 and A549 cells to TRAIL. Therefore, it may be considered as a potential therapeutic agent that enhances the efficacy of TRAIL for the treatment of prostate and non-small human lung cancer.
\end{abstract}

Keywords: Apoptosis, BID, Camptothecin, Cancer cells, TAT peptide, TRAlL

\section{Background}

Susceptibility to apoptosis is impaired in majority of cancer cells. A common reason is reduction of the "functional dose" of apoptotic proteins [1], i.e. decrease of effective concentration of active proteins below a critical level necessary to carry out the process. The main causes of the reduction are: (i) lowered expression of apoptotic proteins, e.g. caspases [2]; (ii) elevated expression of inhibitors of apoptosis proteins (IAPs) that reduce the level of the initiator and effector caspases [3], and (iii) phosphorylation of apoptotic proteins $[4,5]$ that makes them inaccessible to signaling and eventually prevents apoptosis in cancer cells. Reconstruction of the physiological functional

\footnotetext{
* Correspondence: jtd@biol.uw.edu.pl

'Department of Molecular Biology, Faculty of Biology, University of Warsaw, Miecznikowa 1, 02-096 Warsaw, Poland

Full list of author information is available at the end of the article
}

dose of apoptotic protein in protein-deficient cells is a suggested strategy for cancer therapy.

BID (BH3-interacting domain death agonist) protein is situated in extrinsic apoptotic signaling between death receptors and mitochondria [6], and acts as an inductor of permeabilization of the outer mitochondrial membrane in type II cells [7]. The level of BID is critical for viability of numerous cells because its silencing makes them resistant to apoptosis induced by death receptors ligands, e.g. TNF-related apoptosis-inducing ligand (TRAIL) $[8,9]$. Moreover, it has been demonstrated that the level of BID is below the functional dose in cells of several lines because they may be sensitized to TRAIL by overexpression of BID $[8,10,11]$. Due to the above, BID has been considered to be therapeutically exploited [8]. However, to define a way to administer BID several significant issues should be solved. The main one is a control of the level of BID delivered to 
the cell. Although a full-length BID has been shown to participate in apoptotic signaling [12], efficient activation of apoptosis needs a specific cleavage of BID by caspase 8 and production of an active truncated form (tBID) [13]. tBID expressed in cells directly induces apoptosis [10]. Therefore, to exploit selectivity for cancer cells exhibited by some anticancer agents $[14,15]$ sensitization of cells by full-length BID is a preferred strategy. To sensitize cells, overexpressing systems based on the adenovirus [11] or pcDNA vectors $[8,16,17]$ have been commonly used. However, they do not provide a stringent control of the level of BID expression in the cell. As a result, the level of BID in transfected cells exceeded several fold that of the endogenous protein and in some cases a direct activation of apoptosis was observed instead of sensitization of cells to apoptotic stimuli $[10,11,16]$. In according to the above, tBID appears in cells treated with adenovirus vector expressing the full-length BID $[11,16]$.

Another question to be answered is whether there is a critical level of endogenous BID that would be prediction for BID-based therapy. Estimated levels of endogenous BID vary from one cell type to another by a factor of about one hundred [18]. However, efficient use of cellular BID may be hampered due to at least two reasons. Firstly, active tBID is sequestered by $\mathrm{Bcl}-2$ proteins [19]. As a consequence, higher level of BID is necessary to support signaling in cells overexpressing Bcl-2. Next, the level of available BID may be reduced by phosphorylation of the protein by CK2 kinase. The cleavage of BID by caspase 8 that produces tBID has been suggested to be dependent on phosphorylation status of BID regulated by CK2 $[5,20]$. Although BID is a poor substrate for CK2 [21], phosphorylation of BID by CK2 in HeLa cells protects it partially from cleavage by caspase 8 [22]. Therefore, as the level of endogenous BID [18], functioning of TRAIL-induced signaling [23], and activity of CK2 [24] differ in particular cancer cells, some cells may be expected not to respond on elevation of cellular concentration of BID whereas other ones may be sensitized by BID.

An issue to be clarified is also which apoptosis inducing agents could be combined with BID to achieve an anticancer effect. Due to the role of BID in the extrinsic apoptotic signaling sensitization with BID is usually followed by a treatment of cells with death receptors ligands $[8,9]$. From among them soluble human TRAIL (Dulanermin) is considered as a potential anticancer drug. It exhibits cancer-selective effects $[14,15]$. Clinical evidence shows that TRAIL is relatively safe and well tolerated [25], and several treatment strategies based on recombinant soluble TRAIL have been recently built and tested ([26] for review). Attempts have been undertaken to improve delivery of TRAIL to target cells and its therapeutic efficacy [15]. Another cellular role proposed for BID is to mediate DNA damage response [27]. It has been shown that BID promotes intrinsic apoptotic pathway in hepatocellular carcinoma cells (HCC) because they are sensitized to etoposide by overexpression of BID $[17,28]$. However, it is not clear whether sensitization of the intrinsic apoptotic pathway by BID is a general phenomenon or it is limited to HCC, and which DNA damaging agents would be a therapeutic option, if they were combined with BID.

With regard to the potential use of BID as a target in cancer therapy, we addressed here the issues listed above by employing TAT cell penetrating peptide to deliver recombinant BID to cancer cells. TAT peptide is one of the smallest protein-transduction domains [29] considered as a vehicle to deliver proteins into cancer cells in anti-cancer therapies [30]. It was exploited to transport several different apoptotic proteins either individually e.g. $[31,32]$ or as a fusion with domains that specifically confine their action to cancer cells e.g. [33,34]. Prostate cancer PC3 cells were the main subject of this study. They have been isolated from bone metastasis of prostate cancer and retain high metastatic potential. PC3 cells are commonly used as a model of prostate cancer metastasis e.g. $[35,36]$, poorly susceptible to chemotherapy. They are type II cells [37] that use an apoptotic pathway dependent on the presence of BID [38]. CK2 activity in prostate cancer cells is $\sim 3-5$ times higher than in a normal tissue [39] and it influences susceptibility of these cells to apoptosis [40]. Moreover, impairment of apoptosis and not increased proliferation is a main factor in prostate cancer progression [41] making it a promising target for BID-based therapy. To have a better insight into ability of directly delivered BID to sensitize different cancer cells, we also tested three other cancer cell lines: prostate cancer LNCaP, non-small human lung cancer A549 and cervix carcinoma HeLa. TRAIL and camptothecin (CPT) were used to induce apoptosis through either death receptors or DNA damage, respectively. We found that: (i) BID fused with TAT peptide is delivered to cells at the non-toxic dose; (ii) delivered BID sensitized PC3 cells to apoptosis induced by TRAIL and CPT; (iii) out of other cancer cell lines A549 and HeLa cells were sensitized to apoptosis induced by TRAIL and no line to apoptosis induced by CPT; (iv) unphosphorylable mutant of BID sensitized cells similarly as the wild type protein.

\section{Methods}

\section{Cell lines and cell culture}

Experiments were performed using two prostate cancer cell lines (PC3 and LNCaP), and two non-prostate cell lines: non-small human lung cancer A549 and cervix carcinoma HeLa. All cell lines were purchased from the European Collection of Cell Cultures (ECACC). Prostate cancer cells were cultured in RPMI-1640 medium. PC3 medium contained $2 \mathrm{mg} / \mathrm{ml}$ D-glucose. LNCaP medium 
contained $4.5 \mathrm{mg} / \mathrm{ml} \mathrm{D}$-glucose, and additionally $10 \mathrm{mM}$ HEPES and $1 \mathrm{mM}$ sodium pyruvate. Non-small human lung cancer A549 cell line and cervix carcinoma HeLa cell line were cultured in F12K or DMEM medium, respectively. All media were supplemented with $10 \% \mathrm{FBS}$, penicillin $(100 \mathrm{U} / \mathrm{ml})$ and streptomycin $(100 \mu \mathrm{g} / \mathrm{ml})$. Cultures were maintained in a $95 \%$ humidified atmosphere of $5 \% \mathrm{CO}_{2}$ at $37^{\circ} \mathrm{C}$. For experiments cells were seeded in 96- and 24-wells plates or dishes.

\section{Reagents}

Pfx polymerase was obtained from Invitrogen (Thermo Fisher Scientific, USA); Ni-NTA agarose resin, GAPDH antibodies and RPMI-1640 medium from Sigma ALDRICH (Inc. Sigma-Aldrich Corp, MO, USA); F-12 K medium from ATCC (ATTC, VA, USA); Applixchange-G25M from AppliChem (AppliChem GmbH, Darmstadt, Germany); Superdex-200 from Amersham (GE Healthcare Europe $\mathrm{GmbH}$, Austria); anti-Bid antibodies from Santa Cruz Biotechnology, Inc. (Santa Cruz, CA, USA); cytochrome c antibodies and Annexin V-FITC Apoptosis Detection kit I from Becton and Dickinson Bioscience (Becton, Dickinson and Company, New Jersey, USA); Protease Inhibitor Cocktail from Promega (Promega Corporation, USA).

\section{Plasmid construction and mutagenesis}

cDNA corresponding to human BID (BID(L), isoform 1, 195 aa) was amplified by PCR method. Plasmid IRATp 970C1135D (imaGenes) containing full length cDNA BID clone [GenBank: BC036364] was used as a template. To construct pET28a/TAT-BID plasmids encoding a series of BID fusion proteins, bacterial vector pET28a (Novagen) was enriched with sequences coding TAT and repeated three times HA-tag. BID cDNA was cloned into the vector between TAT-sequence and HA-tags. All mutations were introduced into constructed plasmid by sitedirected mutagenesis.

Plasmid for expression of human soluble TRAIL was prepared as described previously [42].

\section{Expression, isolation and purification of recombinant proteins}

Recombinant BID protein fused with TAT peptide was used in this study (Figure 1A). The construct was used either as a wild type protein (TAT-BID) or its mutated variants. In the latter case, the fusion protein mutated at sites phosphorylated by CK2 kinase [21], (TATBID $^{\text {T59A/S76A }}$ ) was used for testing sensitivity of exogenous BID to phosphorylation by CK2 in cancer cells, and the mutant uncleavable by caspase 8 [43] (TAT-BID ${ }^{\mathrm{D} 60 \mathrm{E}}$ ) for testing the processing of delivered recombinant BID in the cell. All the above mentioned proteins were tagged with His-tag used for purification and with HA tag used for simple identification of the protein in the cell. His-tag used for purification and the TAT peptide used for the cell penetration were localized at the $\mathrm{N}$-terminal end of the protein and thus they were removed after cleavage by caspase 8 that makes the protein active. On the other hand, HA tags used for identification of the protein were placed at the $\mathrm{C}$-terminus and remained uncut after proteolytic cleavage.

Recombinant BID was expressed in Escherichia coli BL21(DE3) cells. The proteins were isolated and purified under native conditions using Ni-NTA agarose resin and gel-filtration (Applixchange-G25M) chromatography. Purity of all variants of recombinant TAT-BID is shown on Figure 1B. Recombinant soluble form of human TRAIL [14] was used to induce apoptosis in several experiments. For TRAIL protein expression E. coli M15 [pREP4] (Qiagen) cells were used. TRAIL was purified under native conditions using Ni-NTA agarose resin and then using FPLC on Superdex-200. Purity of TRAIL is shown on Figure 1B. Estimation of the molecular weight identified that nearly $100 \%$ of prepared TRAIL was in an active trimeric form [14] (Figure 1C).

Protein concentration in samples used in the experiments was quantified by densitometry after SDS-polyacrylamide gel electrophoresis using ChemiDocXRS (BioRad).

\section{Uptake of the recombinant proteins by cells}

To examine time-dependent kinetics and concentrationdependence of uptake of the recombinant protein by the cells, TAT-BID was added directly to the culture medium in the presence of trypsin inhibitor from soybean (final concentration $0.005 \%$ ). Then cells were washed 3 times with PBS, trypsinized, collected and centrifuged at $250 \times \mathrm{g}$ for $5 \mathrm{~min}$ at $4^{\circ} \mathrm{C}$. 3 additional series of washing were made and then cells were counted, resuspended in Laemmli buffer $\left(1 \times 10^{4}\right.$ cells $\left./ \mu \mathrm{l}\right)$ and boiled for $20 \mathrm{~min}$, resolved on a polyacrylamide gel under denaturing conditions, and transferred into PVDF membrane. Protein concentration in extracts was measured using Bradford assay [44]. Protein's uptake and the level of endogenous BID were detected by Western blot analysis carried out with the aid of anti-Bid antibodies. The membranes were subsequently stripped of the first antibody and re-probed with anti-GAPDH antibodies. The results were quantified by densitometry using ChemiDocXRS (BioRad).

\section{MTT assay and detection of apoptosis}

MTT mixture [45] was added at the concentration $0.5 \mathrm{mg} / \mathrm{ml}$ for PC3, LNCaP and A549 cells or $2.5 \mathrm{mg} / \mathrm{ml}$ for HeLa cells, after removal of the culture medium. Cells were then cultured for additional $120 \mathrm{~min}$ at $37^{\circ} \mathrm{C}$. The formazan crystals were diluted in DMSO-isopropanol mixture (1:1) and the absorbance was measured at $570 \mathrm{~nm}$ using VICTOR Multilabel Plate Reader (PerkinElmer). For 


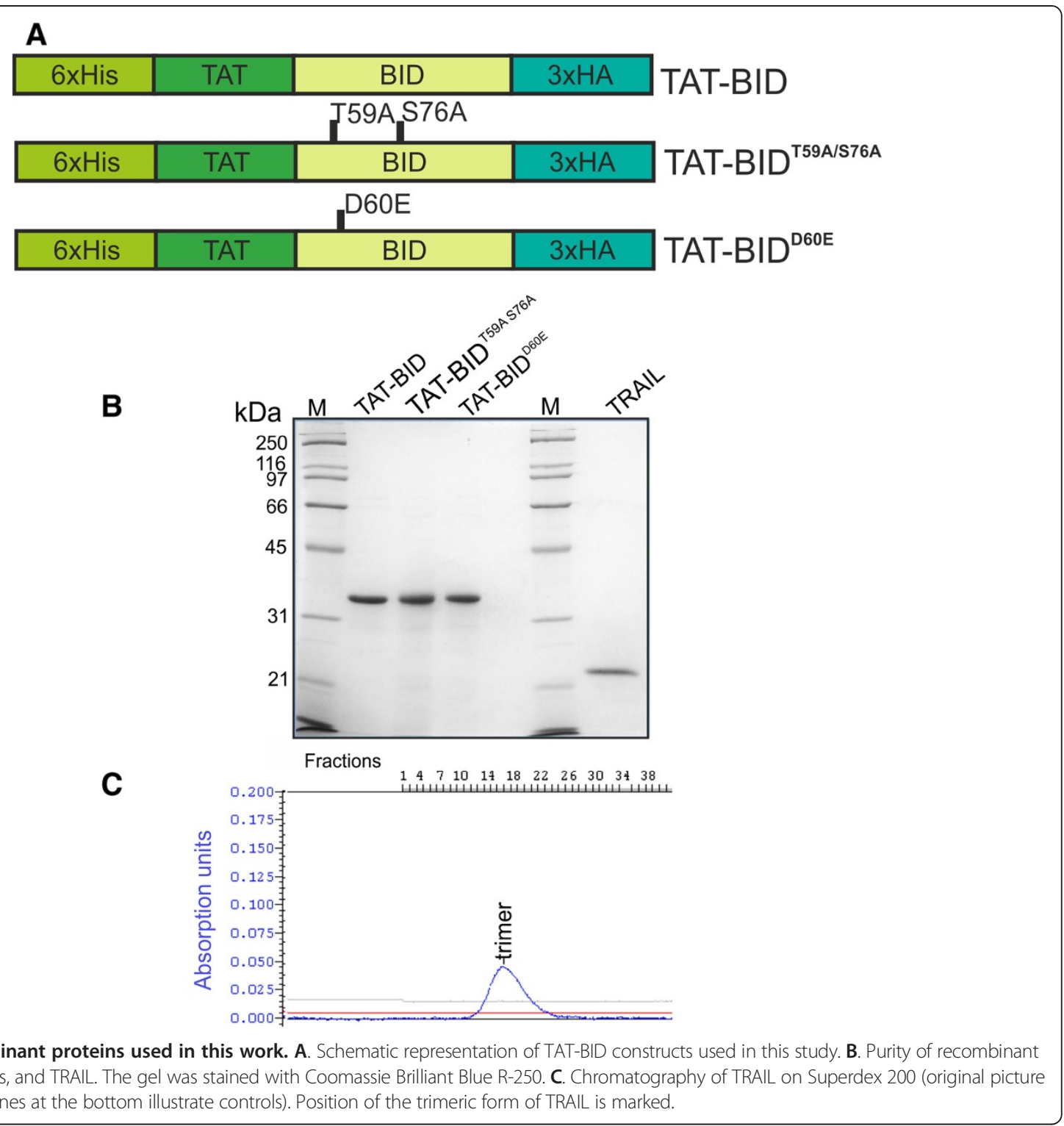

detection of apoptosis PC3 cells were cultured for 24 hours with $30 \mu \mathrm{g} / \mathrm{ml}$ of TAT-BID in the presence of trypsin inhibitor from soybean and $200 \mathrm{ng} / \mathrm{ml}$ TRAIL. Then, both floating and adherent cells were harvested. The floating cells were collected by centrifugation at $700 \times \mathrm{g}$ for $5 \mathrm{~min}$ at $4^{\circ} \mathrm{C}$. Adherent cells were first trypsinized and then collected by centrifugation at $700 \times \mathrm{g}$ for $5 \mathrm{~min}$ at $4^{\circ} \mathrm{C}$. Both fractions were resuspended in Annexin $\mathrm{V}$ binding buffer and pooled. Apoptotic cells were detected by flow cytometry as described previously [42] and analyzed with a BD FACSDiva Software ver. 6.0 (Becton Dickinson).

\section{Cytochrome c assay}

To detect cytochrome c release, cytosol-free mitochondria were prepared. PC3 cells were seeded on $60 \mathrm{~mm}$ dishes and treated with TAT-BID $(30 \mu \mathrm{g} / \mathrm{ml})$, TRAIL $(100 \mathrm{ng} / \mathrm{ml})$ or TAT-BID + TRAIL for 4 hours. Next, both floating and adherent cells were collected, spun at $1000 \mathrm{~g}$ for $5 \mathrm{~min}$ at RT and pellets were resuspended in ice-cold Mito-buffer (20 mM HEPES, pH 7.5, $10 \mathrm{mM}$ $\mathrm{KCl}, 1.5 \mathrm{mM} \mathrm{MgCl}_{2}, 1 \mathrm{mM}$ EGTA, $1 \mathrm{mM}$ EDTA, $1 \mathrm{mM}$ DTT, $250 \mathrm{mM}$ sucrose, $100 \mu \mathrm{M}$ benzamidine, $55 \mu \mathrm{M}$ phenanthroline, $20 \mu \mathrm{M}$ leupeptin, $5 \mu \mathrm{M}$ pepstatin $\mathrm{A}, 1$ $\mathrm{mM}$ PMSF) and lysed on ice by homogenization in a small glass Potter-Elvehjem homogenizer. The homogenates were spun at $800 \mathrm{~g}$ for $10 \mathrm{~min}$ at $4^{\circ} \mathrm{C}$ to remove nuclei and cell detritus and then spun at $16000 \mathrm{~g}$ for 30 min at $4^{\circ} \mathrm{C}$ to pellet the mitochondria. Pellets were washed with Mito-buffer and spun again at $16000 \mathrm{~g}$ for $30 \mathrm{~min}$ at $4^{\circ} \mathrm{C}$ [46]. Cytosol-free mitochondria were lysed in Laemmli buffer, boiled for $10 \mathrm{~min}$ at $95^{\circ} \mathrm{C}$ and used 
for Western blot analysis. Mitochondrial proteins were separated on $15 \%$ polyacrylamide gel and cytochrome c was detected using anti-cytochrome $\mathrm{c}$ antibodies. Also GAPDH protein was detected by Western blot analysis using anti-GAPDH antibodies. The results were quantified by densitometry using ChemiDocXRS (BioRad).

\section{Data analysis}

All experiments were carried out at least in triplicate, and for each individual point at least five independent measurements were done. Differences between groups were calculated using t-Student test. P-Value $<0.05$ was considered statistically significant. The following ranges were defined: $\mathrm{p}<0.05{ }^{(*)}, \mathrm{p}<0.01{ }^{(* * *)}$ and $\mathrm{p}<0.001{ }^{(* * *)}$ ). Statistica ver10 software (StatSoft, Poland) was used for analysis.

\section{Results}

TAT-BID enters PC3 cells in amounts depending on time and dose

To exert an effect on apoptosis TAT-BID had to be efficiently taken up by PC3 cells at a non-toxic dose. Therefore, we firstly examined whether TAT-BID entered PC3 cells, and whether a meaningful amount of recombinant BID appeared in the cells under conditions that not significantly influences their viability. Relatively short drug treatment is necessary for activation of early stages of apoptosis by TRAIL [47] and CPT [48]. We observed this phenomenon also in our experimental system where treatment with TRAIL for $1 \mathrm{~h}$ or with CPT for $2 \mathrm{~h}$ followed by incubation in a TRAIL- and CPT-free medium was enough to induce apoptosis detected after $24 \mathrm{~h}$ in all tested cancer cell lines (not shown). Therefore, to control increase in BID level, we examined the amount of TAT-BID taken up by the cells during the first two hours. We found that TAT-BID alone did not influence viability of PC3 cells by more than 10\% within the range of concentrations used in this work, i.e. up to $40 \mu \mathrm{g} / \mathrm{ml}$ (Figure 2A). Therefore, we examined a dose dependence of transportation of TAT-BID within the range of $0-40 \mu \mathrm{g} / \mathrm{ml}$.

TAT-BID was taken up by PC3 cells in a timedependent (Figure 2B) and a dose-dependent manner (Figure 2C). When the amount of TAT-BID was related to the level of endogenous BID, an amount of cellular BID increased under standard conditions of the treatment $(30 \mu \mathrm{g} / \mathrm{ml}$ for $120 \mathrm{~min}$ ) by about $65 \%$. Taking into account the estimated level of endogenous BID in PC3 cells as $16.0 \pm 4.4 \mathrm{fg} / \mathrm{cell}$, the final level of cellular BID increased due to the treatment up to about $25 \mathrm{fg} / \mathrm{cell}$. Both mutated TAT-BID were taken up in a similar extent as the wild type protein.

\section{TAT-BID sensitizes PC3 cells to apoptosis}

We asked next whether increase of the cellular level of BID achieved due to controlled delivery of the protein resulted in increased sensitivity of PC3 cells to apoptosis induced by TRAIL. We found that TAT-BID increased a number of apoptotic cells that appeared after TRAIL treatment (Figure 3A-E). Such a picture was observed at a TRAIL dose that alone increased a number of apoptotic cells only by about $5-10 \%$ percent (Figure 3A; see also Additional file 1: Figure S1A). TAT-BID elevated this number by about $15-20$ percentage points (Figure 3A) and this increment was relatively stable for higher concentrations of TRAIL (not shown). If calculated number of apoptotic cells was reduced by number of these cells present in the culture under control conditions at low concentrations of TRAIL, sensitization of PC3 cells by TAT-BID resulted in two- threefold increase of apoptosis as compared to cells treated with TRAIL alone (Figure 3A). Pro-apoptotic effect of combined treatment with TAT-BID and TRAIL can be observed on microscope pictures (Figure 3F-I). Increase of the amount of apoptotic cells upon combined TAT-BID + TRAIL-treatment of PC3 cells, as compared to cells treated with TRAIL alone, was also observed as a decrease in viability of the cells (MTT test) (Figure 4A).

Cytotoxicity of TAT peptide has been repeatedly examined and it was found to be low e.g. [49]. However, we would like to know whether the effects described above resulted from participation of recombinant BID in apoptosis and not from any unspecific action of TATBID fusion. To this end we used TAT fused with D60E mutant of TAT-BID that is not cleaved by caspase 8 [43]. We observed that TAT fused with inactive BID (TAT-BID ${ }^{\mathrm{D} 60 \mathrm{E}}$ ) was ineffective in sensitizing PC3 cells to TRAIL (Figure 4B), in spite of the fact that it entered into the cells (Figure 4C) in amounts similar to those of active protein. This indicates that cleavage of BID by caspase 8 [13] is a necessary prerequisite for effective action of TAT-BID.

The unphosphorylable mutant TAT-BID ${ }^{\text {T59AS76A }}$ was similarly effective as the wild type TAT-BID in sensitization of PC3 cells to TRAIL (Figure 4A). This indicates that phosphorylation of BID by CK2 suggested to prevent BID from immediate cleavage by caspase 8 [22] is not a limiting factor for efficacy of TAT-BID in PC3 cells.

BID is active not only in apoptotic signaling between death receptors and mitochondria $[6,13]$ but it also plays a role in the DNA damage response $[17,27]$. Therefore, we asked next whether TAT-BID supported the latter apoptotic pathway in PC3 cells. To examine the effect of delivery recombinant BID on apoptosis induced by DNA damage we used CPT. The cells were sensitized by TAT-BID to CPT at the statistically significant level (Figure 4D); however, the effect was lower for CPT than 

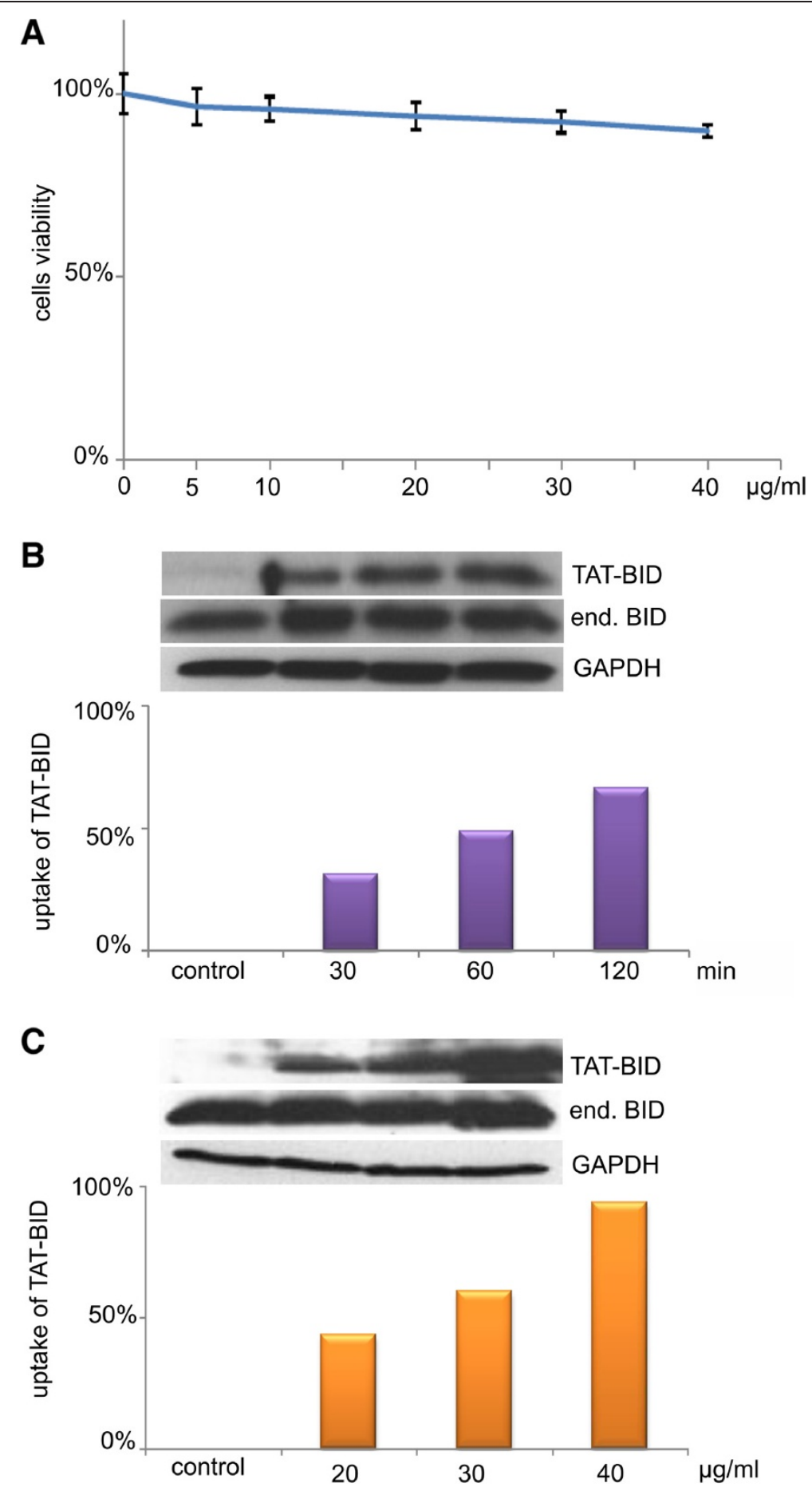

Figure 2 Uptake of TAT-BID by PC3 cells. A. Effect of different doses of TAT-BID on PC3 cells viability. Viability of cells treated with TAT-BID for $24 \mathrm{~h}$ was measured by MTT test. The average of cells viability $( \pm$ SD) was shown. B. Time-dependence of the uptake of TAT-BID by PC3 cells. TAT-BID was added to the medium at a concentration of $30 \mu \mathrm{g} / \mathrm{ml}$. C. Dose-dependence of TAT-BID uptake by PC3 cells. Different doses of TAT-BID were added to the medium for $120 \mathrm{~min}$. TAT-BID and endogenous BID were identified in cell extracts using anti-BID antibodies. GAPDH was used as a loading control. Uptake was expressed as increase in cellular BID (endogenous level of BID was 100\%). 


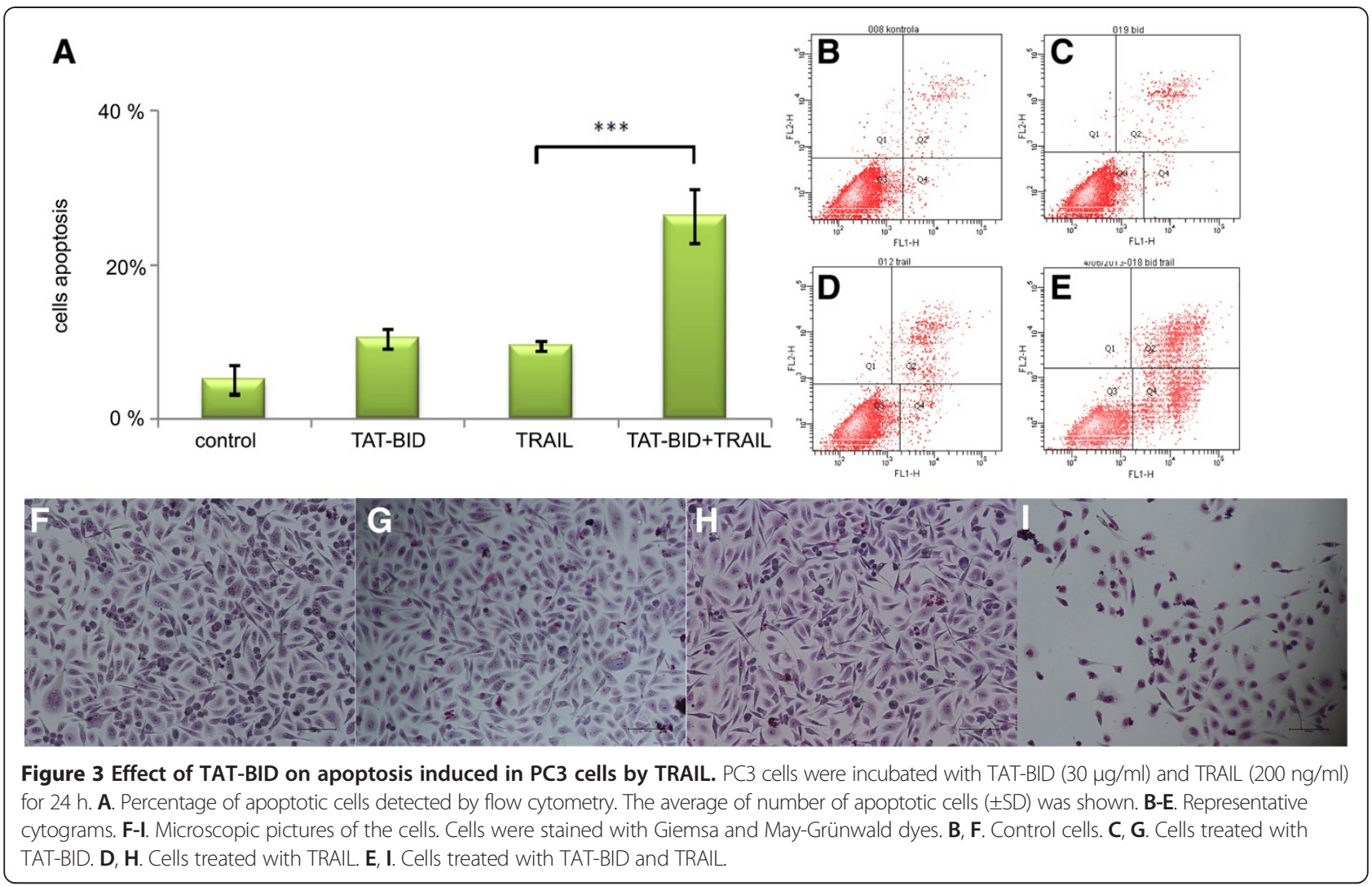

for TRAIL used to induce apoptosis (compare Figures 4A and D). The mutant TAT-BID ${ }^{\mathrm{T} 59 \mathrm{~A} / \mathrm{S} 76 \mathrm{~A}}$ was similarly effective as the wild type TAT-BID in sensitization of PC3 cells to CPT.

\section{TAT-BID improves activation of the mitochondrial pathway in PC3 cells}

We also liked to know whether delivered TAT-BID was used in the cells to improve the mitochondrial cell death pathway. A critical event in the mitochondrial pathway is cytochrome c release [6]. Thus, we examined the effect of TAT-BID on TRAIL-induced cytochrome c release. We observed significant decrease of the amount of cytochrome $\mathrm{c}$ in mitochondrial fraction after combined TAT-BID + TRAIL treatment as compared to TAT-BID or TRAIL administered alone (Figure 5). Glyceraldehyde-3phosphate dehydrogenase (GAPDH), commonly used as a load control because of its stable level, has been reported to accumulate in mitochondria of some cancer cell lines upon induction of apoptosis, and to participate in release of pro-apoptotic proteins from mitochondria [50]. If such a process occurred in PC3 cells, it was not detected by applied methods. However, regardless of whether it occurred or not, the cytochrome c/GAPDH ratio well illustrates activation of mitochondrial cell death pathway because both release of cytochrome $\mathrm{c}$ and putative accumulation of GAPDH are thought to participate in the pathway, and both alter cytochrome c/GAPDH ratio in the same direction. As it can be seen on Figure 5, the ratio was only slightly affected by TAT-BID, more seriously by TRAIL acting alone, and it dramatically dropped when TAT-BID was administered together with TRAIL.

TAT-BID selectively sensitizes other cell lines to TRAIL

The next question we liked to answer was whether TATBID sensitized other cancer cell lines to TRAIL similarly as it was observed for PC3. The prostate cancer cell line LNCaP is TRAIL resistant [51]. However, another TRAILresistant non-small human lung cancer A549 cell line [52] has been shown to get TRAIL sensitivity upon expression of BID from pDNA vector $[8,11]$. Therefore, we tested ability of TAT-BID to sensitize both initially insensitive cell lines to TRAIL. We also used TRAIL-sensitive cervix carcinoma HeLa cells [52]. Estimated levels of endogenous BID in examined cancer cell lines varied from about $10 \mathrm{fg} /$ cell for $\mathrm{LNCaP}$ to about $35 \mathrm{fg} /$ cell for A549 cells (Figure 6A).

Although TAT-BID entered into all examined cells, the taken amount was different for particular cell line and did not depend simply on the level of endogenous BID. The amount of TAT-BID that entered cells was the highest in LNCaP cells, moderate in A549 and low in HeLa cells. When the amount of TAT-BID was related to the level of endogenous BID, a standard treatment with 


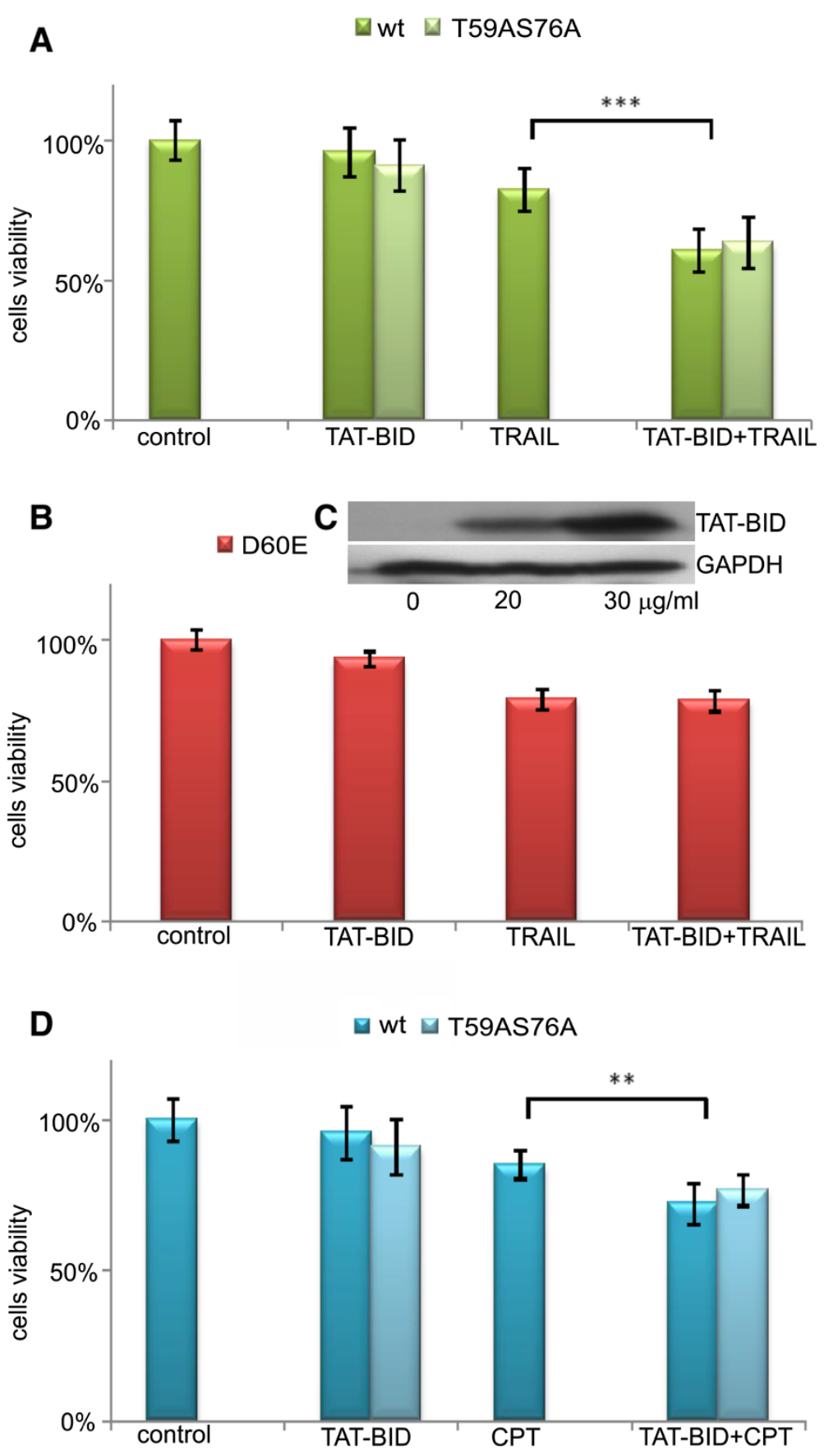

Figure 4 Effect of TAT-BID on viability of PC3 cells treated with TRAIL or CPT. A. Viability of cells treated with $30 \mu \mathrm{g} / \mathrm{ml}$ of the wild type TAT-BID (light bars) or TAT-BID T59AS76A (dark bars) and $100 \mathrm{ng} / \mathrm{ml}$ of TRAll for $24 \mathrm{~h}$. B. Viability of cells treated with $30 \mu \mathrm{g} / \mathrm{ml}$ of TAT-BID ${ }^{\mathrm{D} 60 \mathrm{E}}$ and $200 \mathrm{ng} / \mathrm{ml}$ of TRAIL for $24 \mathrm{~h}$. There is no statistically significant difference between viability of TRAlL- and TAT-BID ${ }^{\text {D60E }}$-treated cells. C. Dose-dependent TAT-BID $^{\text {D60E }}$ uptake by PC3 cells measured after $120 \mathrm{~min}$. D. Viability of cells treated with $30 \mu \mathrm{g} / \mathrm{ml}$ of TAT-BID and $30 \mathrm{nM}$ of CPT. Viability of cells treated with TAT-BID for $24 \mathrm{~h}$ was measured by MTT test. The average of cells viability $( \pm$ SD) was shown. $\mathbf{A}$ and $\mathbf{D}$. Viability of control (control) and TRAIL- or CPT-treated cells (TRAIL or CPT, respectively) are valid in each case for both TAT-BID and TAT-BIDT59AS76A

TAT-BID (30 or $40 \mu \mathrm{g} / \mathrm{ml}$ for $120 \mathrm{~min}$ ) resulted in increase of the amount of cellular BID by $100 \%$ for LNCaP, $60 \%$ for A549 and 20\% for HeLa cells (Figure 6B, D, F). Taking into account levels of endogenous BID in the cell lines (Figure 6A), one could calculate that after TATBID treatment total amount of BID was within the range $20-25 \mathrm{fg} /$ cell for LNCaP and HeLa cells, and about $60 \mathrm{fg} / \mathrm{cell}$ for A549 cells. 


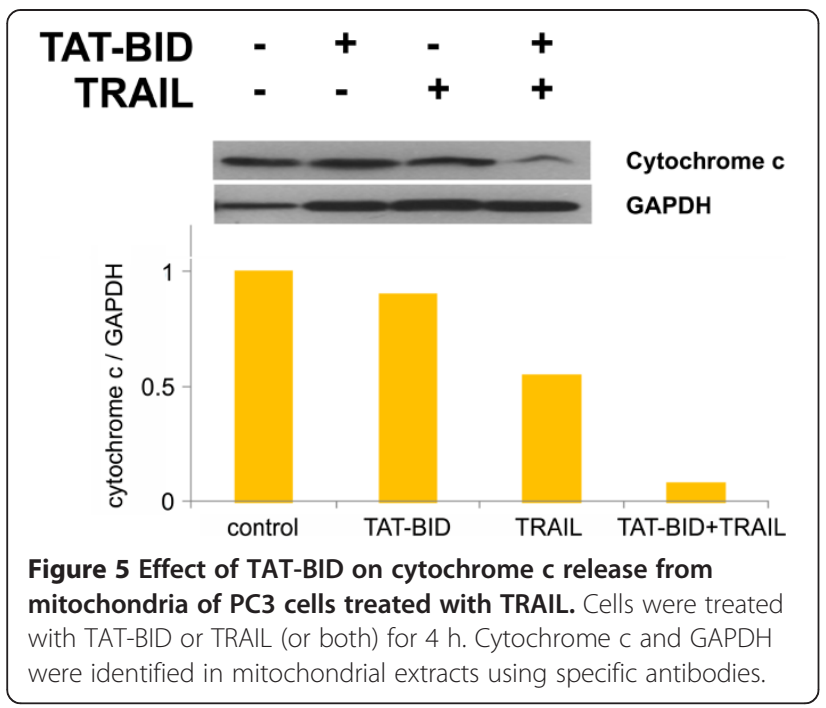

Similarly as in the case of PC3 cells, TAT-BID did not influence viability of remaining cell lines by more than $10 \%$, at least up to the dose of $40 \mu \mathrm{g} / \mathrm{ml}$ (Additional file 2: Figure S2). TRAIL administered alone at the dose of $100 \mathrm{ng} / \mathrm{ml}$ affected viability of neither A549 nor LNCaP cells by more than 5\% (Additional file 1: Figure S1B, C). In the latter case, no significant changes in cell viability were observed at concentration as high as $1000 \mathrm{ng} / \mathrm{ml}$. On the contrary, at the TRAIL dose of $100 \mathrm{ng} / \mathrm{ml}$ TRAIL alone decreased HeLa cells viability by about 40 - 50\% (Additional file 1: Figure S1D).

To compare effects of TAT-BID on different cell lines, we generally used the dose of $100 \mathrm{ng} / \mathrm{ml}$ TRAIL (Figure 6C, E, G). At this dose the effect of TAT-BID on sensitivity of LNCaP was not statistically significant (Figure 6C). Neither was it observed at higher TRAIL doses, up to $500 \mathrm{ng} / \mathrm{ml}$ (not shown). A549 cells were sensitized by TAT-BID to TRAIL similarly as PC3 cells (Figure 6E). HeLa cells were only slightly sensitized to TRAIL (Figure 6G). Increase of concentration of TATBID in the medium up to $50 \mu \mathrm{g} / \mathrm{ml}$ did not change a picture presented on Figure 6C, E, G (not shown). Similarly as it was observed for PC3 cells, unphosphorylable mutant TAT-BID ${ }^{\text {T59A/S76A }}$ sensitizes neither A549 nor HeLa cells to TRAIL better than the wild type TAT-BID. It was also ineffective towards LNCaP cells (not shown). None cell line other than PC3 was sensitized by TAT-BID to CPT.

\section{Discussion}

The main finding of this work is that direct delivery of recombinant BID fused with the TAT cell penetrating peptide allows for controlled sensitization of cancer cells to apoptosis induced by TRAIL and CPT. Its results are primarily relevant to potential use of recombinant BID directly delivered to cells in anticancer therapy; however, the work clarifies also some points concerning functioning of BID in different cancer cells.

Importance of BID for apoptosis has been reported for several cancer cell lines that became either more sensitive to apoptosis after expression of BID or more resistant to it after silencing expression of the protein [8-11]. Those reports raised also a question of therapeutic potential of the overexpressed BID that would act alone $[8,10]$ or combined with chemotherapy for cancer cells [11]. However, to confine effects of extra BID only to cancer cells it has to be applied in low amounts, not enough to kill the cells but rather to sensitize them to agents that induce apoptosis. The system described in this paper fulfills this condition because direct delivery of TAT-BID allows for stringent control of the amount of BID in particular type of cancer cells. As an alternative to expression from DNA vectors, cell penetrating peptides offer fast, efficient and dose-dependent transport of proteins required for their therapeutic use [31]. Such characteristics was observed in this work for TATBID uptake (Figures 2 and 6) and thus pointed to the potential of BID fused with TAT as a therapeutic strategy.

The results presented here show that TAT-BID sensitizes PC3, A549 and to very low extent HeLa cells to apoptosis induced by TRAIL, but it fails to sensitize LNCaP cells. Looking for explanation of this picture we firstly analyzed transportation of TAT-BID into cells. Different cell lines do not show the same efficiency of the uptake of cell penetrating peptides conjugates [53]. It was also observed by us that transportation occurred with different efficacy in particular cell lines: it was high for LNCaP cells, slightly lower for PC3 and A549 cells and very low for HeLa cells. In the latter case poor transportation of TAT-BID correlated with low detectable sensitization of HeLa cells to TRAIL although a cause and effect relationship between the two phenomena was not proved here. However, transportation into cancer cells has to be considered as a factor that could influence therapeutic use of TAT-BID. Another question to be answered was why TAT-BID overcame TRAIL resistance of A549 but not LNCaP cells, despite of satisfactory transportation of TAT-BID into cells of both cell lines. As concerns the first cell line, this is in agreement with previous findings that expression of BID from pDNA expression vector sensitizes A549 cell to apoptosis induced by TRAIL $[8,11]$. It seems probable that different effects of TAT-BID on LNCaP and A549 result from different sites at which defects in TRAIL-induced signaling are localized. In LNCaP cells the signaling is impaired upstream of BID at the stage of c-FLIP [51,54], whereas in A549 cells downstream of BID at the stage of $\mathrm{Bcl}-2$ that is overexpressed in these cells $[55,56]$. In the latter case total amount of cellular BID necessary to make A549 cells sensitive to TRAIL was significantly 


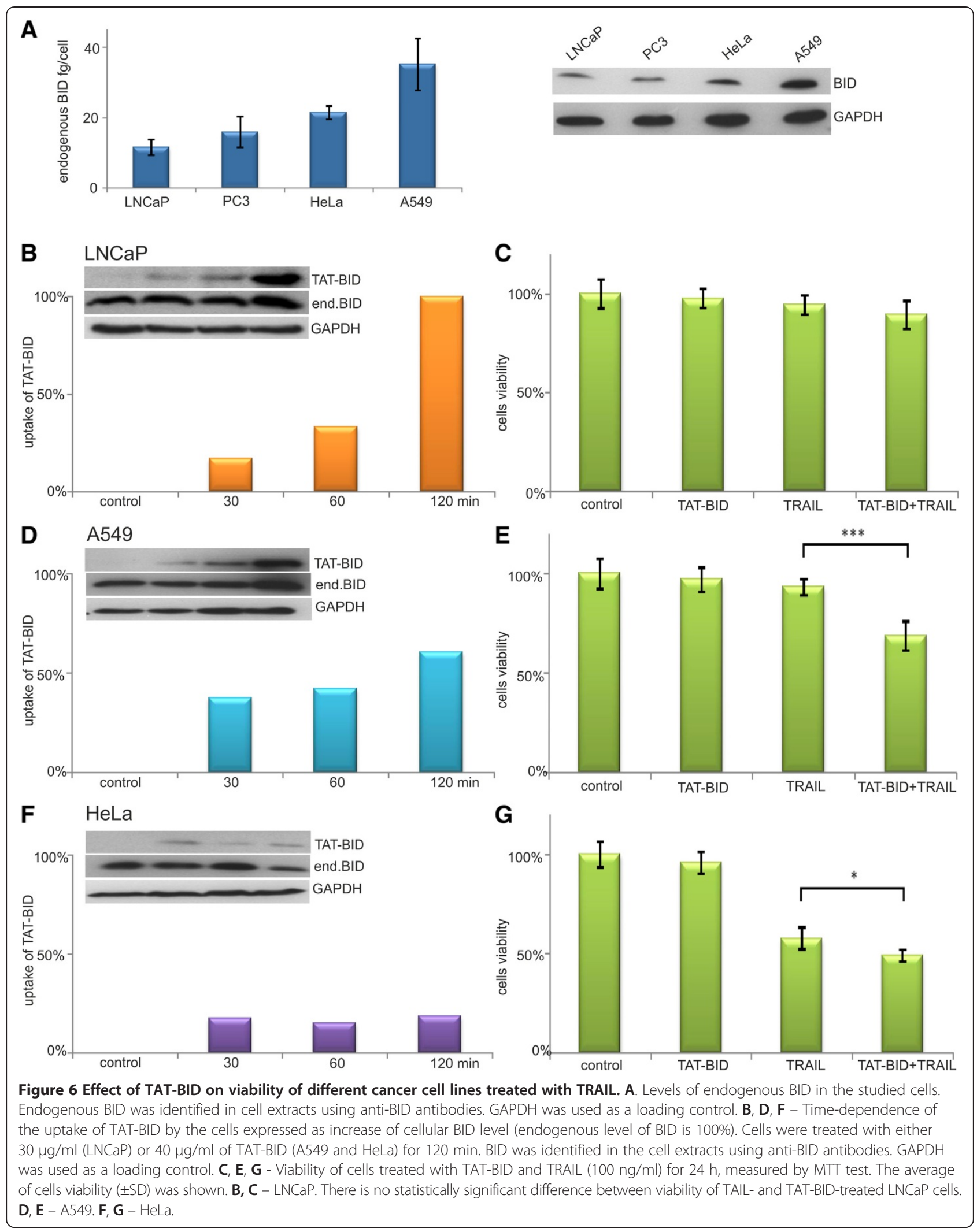


higher than that effective in PC3 cells (Figures 2 and 6). Since Bcl-2 sequesters active tBID and this way prevents cells from killing [19], it is probable that more BID is necessary in A549 than in PC3 cells to start apoptosis. The above observation also indicates that estimation of a level of endogenous BID cannot be a prediction of sensitivity of cancer cells to TAT-BID.

We showed here that TAT-BID sensitized PC3 cells to apoptosis induced by DNA damage introduced by CPT (Figure 4D) although sensitization to CPT was clearly weaker than that to TRAIL. The question was why PC3 but not any other cell line examined in this work was sensitized to CPT by excess of BID. The pronounced determinant of PC3 making them distinct from other cells used here is lack of active p53 [57] that mediates main cellular response to DNA damage. It might be thus thought that p53-indepentent apoptosis following CPTinduced DNA damage in PC3 cells was more prone to BID level than that activated in cells containing active p53. A functional connection between BID and p53 has been shown in HCC cells [17]. It has also been shown that cells of HCC line bearing mutated inactive p53 are sensitized by overexpressed BID to DNA damage introduced by etoposide [28] to the extent similar to that observed here for PC3 cells sensitized by TAT-BID to CPT.

Although direct comparison of CK2 activity in all four cell lines studied here has not been done, several reports provide evidence for elevated activity in each case $[22,24,58]$. However, our results indicated that CK2mediated phosphorylation neither influenced efficacy of TAT-BID delivered to PC3 and A549 nor contributed to lack of effect of TAT-BID on LNCaP and to poor sensitization of HeLa cells. Therefore, sensitization of cancer cells to apoptosis based on substitution of BID by its unphosphorylable analogue does not seem to be better strategy at least for cancer lines studied in this work.

TAT is not specific to cancer cells and additional mechanisms have to be employed to restrict sensitization made by TAT-BID to tumors. An obvious solution is a combined treatment including TAT-BID and an anticancer drug that is cancer cells-specific. This is a case of TRAIL that induces apoptosis in cancer but not in normal cells [15], and that has been shown here as effective against PC3 and A549 cells if combined with TAT-BID. Another possibility is to fuse TAT-BID with additional cassette that restricts its action to tumor cells. Such a cassette is ODD domain [59] that accelerates degradation of the fusion protein under normoxia, whereas the fusion protein remains stable under hypoxia conditions, i.e. inside tumors. Results of our ongoing investigations indicate that TAT-BID collaborate well with ODD cassette. These preliminary results show that enrichment of TAT-BID in additional targeting cassette is a promising way to improve its specificity to cancer cells.

\section{Conclusions}

In summary, our results indicate that recombinant BID fused with TAT peptide may be delivered to cells in controlled manner so that it is not toxic but it sensitizes cancer cells to apoptosis. The results point to possible therapeutic potential of BID fused with TAT for cancer treatment. If applied to cell cultures, controlled delivery of BID allows for simple examination of sensitivity of different cancer cells to BID-based therapies and of efficacy of different agents in the treatment combined with BID. The findings presented here indicate that PC3 and A549 cells are good targets for TAT-BIB, and that TRAIL is particularly effective if combined with TAT-BID.

\section{Additional files}

Additional file 1: Figure S1. Effect of TRAIL on viability of the used cell lines. Viability of cells was measured by MTT test. The average of cells viability $( \pm S D)$ is shown. Red $-100 \mathrm{ng} / \mathrm{ml}$; blue $-500 \mathrm{ng} / \mathrm{ml}$; black - $1000 \mathrm{ng} / \mathrm{ml}$

Additional file 2: Figure S2. Effect of TAT-BID on viability of LNCaP, A549 and HeLa cells. Viability of cells treated with TAT-BID for $24 \mathrm{~h}$ was measured by MTT test. The average of cells viability $( \pm S D)$ is shown. Pink - LNCaP; yellow - A549; green - HeLa cells.

\section{Abbreviations}

BID: BH3-interacting domain death agonist; CPT: Camptothecin; TAT-BID: Recombinant BID fused with TAT cell penetrating peptide; tBID: Truncated form of BID; TRAIL: Recombinant soluble TNF-related apoptosis inducing ligand.

\section{Competing interests}

The authors declare that they have no competing interests.

\section{Authors' contributions}

EO and JTD participated in the design of the study and performed most of the experiments; EO also carried out statistic analysis. EK participated in flow cytometry. AC made contribution to proteins' production. PK carried out microscopy. KS participated in the design of the study and wrote the manuscript. All authors read and approved the final manuscript.

\section{Acknowledgements}

We thank Dr Takao Ishikawa for construction of the plasmid coding TAT sequence. This work was financially supported by grants from Ministry of Science and Higher Education through the Faculty of Biology, University of Warsaw intramural grants (No. 501/86-102341 BW and 501/86-104913 DSM) and by Polish Committee for Scientific Research Grant No. N N301 308837.

\section{Author details}

${ }^{1}$ Department of Molecular Biology, Faculty of Biology, University of Warsaw, Miecznikowa 1, 02-096 Warsaw, Poland. '2Department of Immunology, Faculty of Biology, University of Warsaw, Miecznikowa 1, 02-096 Warsaw, Poland.

Received: 22 May 2014 Accepted: 11 October 2014

Published: 18 October 2014

\section{References}

1. Barata JT: The impact of PTEN regulation by CK2 on PI3K-dependent signaling and leukemia cell survival. Adv Enzyme Regul 2011, 51:37-49.

2. Winter RN, Kramer A, Borkowski A, Kyprianou N: Loss of caspase-1 and caspase-3 protein expression in human prostate cancer. Cancer Res 2001, 61:1227-1232

3. Hunter AM, LaCasse EC, Korneluk RG: The inhibitors of apoptosis (IAPs) as cancer targets. Apoptosis 2007, 12:1543-1568. 
4. Fernald K, Kurokawa M: Evading apoptosis in cancer. Trends Cell Biol 2013, 23:620-633.

5. Duncan JS, Turowec JP, Vilk G, Li SSC, Gloor GB, Litchfield DW: Regulation of cell proliferation and survival: convergence of protein kinases and caspases. Biochim Biophys Acta 1804, 2010:505-510.

6. Kantari C, Walczak H: Caspase-8 and bid: caught in the act between death receptors and mitochondria. Biochim Biophys Acta 1813, 2011:558-563.

7. Barnhart BC, Alappat EC, Peter ME: The CD95 type I/type II model. Seminars Immunol 2003, 15:185-193.

8. Tsuno T, Mejido J, Zhao T, Phillips T, Myers TG, Bekisz J, Zoon KC: BID is a critical factor controlling cell viability regulated by IFN-a. J Immunother 2012, 35:23-31.

9. Goncharenko-Khaider N, Lane D, Matte I, Rancourt C, Piche A: The inhibition of Bid expression by Akt leads to resistance to TRAIL-induced apoptosis in ovarian cancer cells. Oncogene 2010, 29:5523-5536.

10. Miao J, Chen GG, Chun SY, Yun JP, Chak ECW, Ho RLK, Lai PBS: Adenovirus-mediated tBid overexpression results in therapeutic effects on p53-resistant hepatocellular carcinoma. Int J Cancer 2006, 119:1985-1993.

11. Fukazawa T, Walter B, Owen-Schaub LB: Adenoviral Bid overexpression induces caspase-dependent cleavage of truncated Bid and p53-independent apoptosis in human non-small cell lung cancers. J Biol Chem 2003, 278:25428-25434

12. Sarig R, Zaltsman Y, Marcellus RC, Flavell R, Mak TW, Gross A: BID-D59A is a potent inducer of apoptosis in primary embryonic fibroblasts. $J$ Biol Chem 2003, 278:10707-10715.

13. Billen LP, Shamas-Din A, Andrews DW: Bid: a Bax-like BH3 protein. Oncogene 2009, 27(Suppl 1):93-104.

14. Walczak H, Miller RE, Ariail K, Gliniak B, Griffith TS, Kubin M, Chin W, Jones J, Woodward A, Le T, Smith C, Smolak P, Goodwin RG, Rauch CT, Schuh JC, Lynch DH: Tumoricidal activity of tumor necrosis factor-related apoptosis-inducing ligand in vivo. Nat Med 1999, 5:157-163.

15. Stuckey DW, Shah K: TRAIL on trial: preclinical advances in cancer therapy. Trends Molec Med 2013, 19:685-694.

16. Yi X, Yin XM, Dong Z: Inhibition of Bid-induced apoptosis by Bcl-2. tBid insertion, Bax translocation, and Bax/Bak oligomerization suppressed. J Biol Chem 2003, 278:16992-16999.

17. Song G, Chen GG, Chau DKF, Miao J, Lai PBS: Bid exhibits $S$ phase checkpoint activation and plays a pro-apoptotic role in response to etoposide-induced DNA damage in hepatocellular carcinoma cells. Apoptosis 2008, 13:693-701.

18. Krajewska M, Zapata JM, Meinhold-Heerlein I, Hedayat H, Monks A, Bettendorf H, Shabaik A, Bubendorf B, Kallioniemi OP, Kim H, Reifenberger $\mathrm{G}$, Reed JC, Krajewski S: Expression of $\mathrm{BCl}-2$ family member Bid in normal and malignant tissues. Neoplasia 2002, 4:129-140.

19. Cheng EHY, Wei M, Weiler S, Flavell RA, Mak TW, Lindsten T, Korsmeyer SJ: $\mathrm{BCL}-2, \mathrm{BCL}-\mathrm{X}_{\mathrm{L}}$ sequester $\mathrm{BH} 3$ domain-only molecules preventing BAX- and BAK-mediated mitochondrial apoptosis. Mol Cell 2001, 8:705-711.

20. Desagher S, Osen-Sand A, Montessuit S, Magnenat E, Vilbois F, Hochmann A, Journot L, Antonsson B, Martinou JC: Phosphorylation of Bid by casein kinases I and II regulates its cleavage by caspase 8 . Mol Cell 2001, 8:601-611.

21. Olsen $B B$, Petersen J, Issinger OG: BID, an interaction partner of protein kinase CK2a. Biol Chem 2006, 387:441-449.

22. Hellwig CT, Ludwig-Galezowska AH, Concannon CG, Litchfield DW, Prehn $J$, Rehm M: Activity of protein kinase CK2 uncouples Bid cleavage from caspase-8 activation. J Cell Sci 2010, 123:1401-1406.

23. Mahalingam D, Szegezdi E, Keane M, de Jong S, Samali A: TRAIL receptor signalling and modulation: are we on the right TRAIL? Cancer Treat Rev 2009, 35:280-288.

24. Bandyopadhyay K, Gjerset RA: Protein kinase CK2 is a central regulator of topoisomerase I hyperphosphorylation and camptothecin sensitivity in cancer cell lines. Biochemistry 2011, 50:704-714.

25. Herbst RS, Eckhardt SG, Kurzrock R, Ebbinghaus S, O'Dwyer PJ, Gordon MS Novotny W, Goldwasser MA, Tohnya TM, Lum BL, Ashkenazi A, Jubb AM, Mendelson DS: Phase I dose-escalation study of recombinant human Apo2L/TRAIL, a dual proapoptotic receptor agonist, in patients with advanced cancer. J Clin Oncol 2010, 28:2839-2846.

26. Hellwig CT, Rehm M: TRAIL signaling and synergy mechanisms used in TRAIL-based combination therapies. Mol Cancer Ther 2012, 11:3-13.
27. Liu Y, Bertram CC, Shi Q, Zinkel SS: Proapoptotic Bid mediates the Atr-directed DNA damage response to replicative stress. Cell Death Differ 2011, 18:841-852.

28. Li Y, Dai C, Li J, Wang W, Song G: Bid-overexpression regulates proliferation and phosphorylation of Akt and MAPKs in response to etoposide-induced DNA damage in hepatocellular carcinoma cells. OncoTargets and Therapy 2012, 5:279-286.

29. Vives $E$, Brodin $P$, Leblus B: A truncated TAT basic domain rapidly translocates through the plasma membrane and accumulates in the nucleus. J Biol Chem 1997, 272:16010-16017.

30. Bitler BG, Schroeder JA: Anti-cancer therapies that utilize cell penetrating peptides. Recent Pat Anticancer Drug Discov 2010, 5:99-108.

31. Essafi M, Baudot AD, Mouska X, Cassuto JP, Ticchioni M, Deckert M: Cell-penetrating TAT-FOXO3 fusion proteins induce apoptotic cell death in leukemic cells. Mol Cancer Ther 2011, 10:37-46.

32. Xingyuan M, Wenyun Z, Dongzhi W, Yushu M, Tianwen W, Jinzhi W, Qinghai $L$, Shengli $Y$ : High-level expression, purification and proapoptosis activity of HIV-TAT-survivin (T34A) mutant to cancer cells in vitro. J Biotechnol 2006, 123:367-378.

33. Zhao Y, Wu S, Wu J, Jia P, Gao S, Yan X, Wang Y: Introduction of hypoxiatargeting p53 fusion protein for the selective therapy of non-small cell lung cancer. Cancer Biol Ther 2011, 11:95-107.

34. Li B, Zhang LJ, Zhang ZL, Long M, Ren JH, Lin F, Wang X, Wei JX, Dong K, Zhang HZ: Synergistic tumor growth-inhibitory effect of the prostatespecific antigen-activated fusion peptide BSD352 for prostate cancer therapy. Anticancer Drug 2011, 22:213-222.

35. Kim JK, Jung Y, Wang J, Joseph J, Mishra A, Hill EE, Krebsbach PH, Pienta K, Shiozawa Y, Taichman RS: TBK1 regulates prostate cancer dormancy through mTOR inhibition. Neoplasia 2013, 15:1064-1074.

36. Ono M, Inkson CA, Sonn R, Kilts TM, de Castro LF, Maeda A, Fisher LW, Robey PG, Berendsen AD, Li L, McCartney-Francis N, Brown AC, Crawford NP, Molinolo A, Jain A, Fedarko NS, Young MF: WISP1/CCN4: a potential target for inhibiting prostate cancer growth and spread to bone. PLoS One 2013, 8:e71709.

37. Munshi A, Pappas G, Honda T, McDonnell TJ, Younes A, Li Y, Meyn RE: TRAIL (APO-2 L) induces apoptosis in human prostate cancer cells that is inhibitable by Bcl-2. Oncogene 2001, 20:3757-3765.

38. Gewies A, Rokhlin OW, Cohen MB: Cytochrome $c$ is involved in Fas-mediated apoptosis of prostatic carcinoma cell lines. Cancer Res 2000, 60:2163-2168

39. Tawfic S, Yu S, Wang H, Faust R, Davis A, Ahmed K: Protein kinase CK2 signal in neoplasia. Histol Histopathol 2001, 16:573-582.

40. Slaton JW, Unger GM, Sloper DT, Davis AT, Ahmed K: Induction of apoptosis by antisense CK2 in human prostate cancer xenograft model. Mol Cancer Res 2004, 2:712-721.

41. Kyprianou N, Bruckheimer EM, Guo Y: Cell proliferation and apoptosis in prostate cancer: significance in disease progression and therapy. Histol Histopathol 2000, 15:1211-1223

42. Orzechowska E, Kozlowska E, Staron K, Trzcinska-Danielewicz J: Time schedule-dependent effect of the CK2 inhibitor TBB on PC-3 human prostate cancer cell viability. Oncol Rep 2012, 27:281-285.

43. Li H, Zhu H, Xu C, Yuan J: Cleavage of BID by caspase 8 mediates the mitochondrial damage in the Fas pathway of apoptosis. Cell 1998, 94:491-501.

44. Compton SJ, Jones CG: Mechanism of dye response and interference in the Bradford protein assay. Anal Biochem 1985, 151:369-374.

45. Twentyman PR, Luscombe M: A study of some variables in a tetrazolium dye (MTT) based assay for cell growth and chemo-sensitivity. $\mathrm{Br} J$ Cancer 1987, 56:279-285.

46. Rokhlin OW, Guseva N, Tagiyev A, Knudson M, Cohen MB: Bcl-2 oncoprotein protects the human prostatic carcinoma cell line PC3 from TRAIL-mediated apoptosis. Oncogene 2001, 20:2836-2843.

47. Hellwig CT, Kohler BF, Lehtivarjo AK, Dussmann H, Courtney MJ, Prehn JHM, Rehm M: Real time analysis of tumor necrosis factor-related apoptosis-inducing ligand/cycloheximide-induced caspase activities during apoptosis initiation. J Biol Chem 2008, 283:21676-21685.

48. Bergeron S, Beauchemin M, Bertrand R: Camptothecin- and etoposide-induced apoptosis in human leukemia cells is independent of cell death receptor-3 and -4 aggregation but accelerates tumor necrosis factor-related apoptosis-inducing ligand-mediated cell death. Mol Cancer Ther 2004, 3:1659-1669. 
49. Aroui S, Brahim S, De Waard M, Kenani A: Cytotoxicity, intracellular distribution and uptake of doxorubicin and doxorubicin coupled to cell-penetrating peptides in different cell lines: A comparative study. Biochem Biophys Res Commun 2010, 391:419-425.

50. Tarze A, Deniaud A, Le Bras M, Maillier E, Molle D, Larochette N, Zamzami N, Jan G, Kroemer G, Brenner C: GAPDH, a novel regulator of the pro-apoptotic mitochondrial membrane permeabilization. Oncogene 2007, 26:2606-2620.

51. Zhang X, Jin TG, Yang H, DeWolf WC, Khosravi-Far R, Olumi AF: Persistent c-FLIP(L) expression is necessary and sufficient to maintain resistance to tumor necrosis factor-related apoptosis-inducing ligand-mediated apoptosis in prostate cancer. Cancer Res 2004, 64:7086-7091.

52. Qiu F, Hu M, Tang B, Liu X, Zhuang H, Yang J, Hua Z: Annexin V-TRAIL fusion protein is a more sensitive and potent apoptotic inducer for cancer therapy. Sci Rep 2013, 3:3565:1-9.

53. Sarko D, Beijer B, Garcia Boy R, Nothelfer EM, Leotta K, Eisenhut M, Altmann A, Haberkorn U, Mier W: The pharmacokinetics of cell-penetrating peptides. Mol Pharm 2010, 7:2224-2231

54. Nesterov A, Lu X, Johnson M, Milleri GJ, Ivashchenko Y, Kraft AS: Elevated Akt activity protects the prostate cancer cell line LNCaP from TRAIL-induced apoptosis. J Biol Chem 2001, 276:10767-10774.

55. Yang TM, Barbone D, Fennell DA, Broaddus VC: BCl-2 family proteins contribute to apoptotic resistance in lung cancer multicellular spheroids. Am J Respir Cell Mol Biol 2009, 41:14-23.

56. Lirdprapamongkol K, Sakurai H, Abdelhamed S, Yokoyama S, Athikomkulchai S, Viriyaroj A, Awale S, Ruchirawat S, Svasti J, Saiki I: Chrysin overcomes TRAIL resistance of cancer cells through Mcl-1 downregulation by inhibiting STAT3 phosphorylation. Oncol Rep 2013, 30:2357-2364.

57. He Z, Zhang Y, Mehta SK, Pierson DL, Wu H, Rohde LH: Expression profile of apoptosis related genes and radio-sensitivity of prostate cancer cells. J Radiat Res 2011, 52:743-751.

58. Scaglioni PP, Yung TM, Cai LF, Erdjument-Bromage H, Kaufman AJ, Singh B, Teruya-Feldstein J, Tempst P, Pandolfi PP: A CK2-dependent mechanism for degradation of the PML tumor suppressor. Cell 2006, 126:269-283.

59. Huang LE, Gu J, Schau M, Bunn HF: Regulation of hypoxia-inducible factor 1alpha is mediated by an $\mathrm{O}_{2}$-dependent degradation domain via the ubiquitin-proteasome pathway. Proc Natl Acad Sci USA 1998, 95:7987-7992.

doi:10.1186/1471-2407-14-771

Cite this article as: Orzechowska et al:: Controlled delivery of BID protein fused with TAT peptide sensitizes cancer cells to apoptosis. BMC Cancer 2014 14:771.

\section{Submit your next manuscript to BioMed Central and take full advantage of:}

- Convenient online submission

- Thorough peer review

- No space constraints or color figure charges

- Immediate publication on acceptance

- Inclusion in PubMed, CAS, Scopus and Google Scholar

- Research which is freely available for redistribution 